\title{
ASPEK SOSIOLOGI SASTRA DALAM NOVEL MENGGAPAI MATAHARI KARYA DERMAWAN WIBISONO
}

\author{
Ryan Hidayat \\ Program Studi Arsitektur, FTMIPA Universitas Indraprasta PGRI \\ Jl.Nangka 58 Tanjung Barat Jagakarsa Jakarta Selatan \\ email :ryansastra3@gmail.com
}

DOI: $\underline{10.26858 / \text { retorika.v 10i2.4855 }}$

\begin{abstract}
The Novel Analysis Menggapai Matahari created by Dermawan Wibisono viewed from the sociology aspect of literary. The purpose of this research is to described the aspects of sociology the work of literature in Menggapai Matahari. The methodology used in this research was a method of from the analysis of the contents of the descriptive. The novel have been analyzed based on the aspect of sociology literature, (1) the element of a social system: a political system as many as 3 points, a system of belief as many as 7 points, the economic system as many as 2 points, and the system of education as many as 7 points, (2) value system as many as 2 points and a system of an idea as many as 3 points, and (3) surveillance equipment sent to the culture as many as 3 points.
\end{abstract}

\begin{abstract}
Abstrak. Analisis Novel Menggapai Matahari Karya Dermawan Wibisono Ditinjau dari Aspek Sosiologi Karya Sastra. Tujuan penelitian ini adalah untuk mendeskripsikan aspek sosiologi karya sastra pada novel Menggapai Matahari. Penelitian ini menggunakan metode deskriptif dengan analisis isi. Novel dianalisis berdasarkan aspek sosiologi sastra, yaitu (1) unsur sistem sosial: sistem politik sebanyak 3 poin, sistem kepercayaan sebanyak 7 poin, sistem ekonomi sebanyak 2 poin, dan sistem pendidikan sebanyak 7 poin, (2) sistem nilai sebanyak 2 poin dan sistem ide sebanyak 3 poin, dan (3) peralatan budaya sebanyak 3 poin.
\end{abstract}

Kata kunci: sosiologi sastra, novel, menggapai matahari

Sastra merupakan suatu pencerminan kehidupan masyarakat. Setiap karya sastra dapat mengungkapkan jalan cerita yang dialami oleh seseorang (tokoh) dan aspek-aspek kehidupan manusia dan kemanusiaan yang lebih mendalam. Aspek kemanusiaan itu akan menjelaskan peristiwa dengan berbagai macam problema yang berhubungan dengan konflik kehidupan. Dalam kaitannya dengan sastra, tidak hanya karya berupa novel saja, tetapi ada puisi, cerpen, drama, hikayat, syair, pantun.

Teeuw memberikan definisi sastra berdasarkan asal-usul katanya (etimologis).

"Sebagai bahan bandingan kata Sastra dalam bahasa Indonesia berasal dari bahasa Sansekerta: akar kata sas- dalam kata kerja turunan berarti mengarahkan, mengajar, memberi petunjuk atau instruksi. Akhiran kata -tra biasanya menunjukkan alat, sarana. Maka dari itu Sastra dapat diartikan alat untuk mengajar, buku petunjuk, buku instruksi, atau pengajaran, misalnya Silpasastra (buku arsitektur), Kamasustra (bu$\mathrm{ku}$ mengenai seni cinta). Awalnya Suberarti baik, indah sehingga Susastra dapat dibandingkan dengan bellesletters (Teeuw, 1984 : 44).

Menurut Wellek dan Warren dalam teori kesusastraan, sastra adalah suatu kegiatan kreatif, sebuah karya seni (Wellek dan Warren, 1997:3). Sebagai seni kreatif yang menggunakan manusia dan segala macam seni kehidupannya, maka ia tidak saja merupakan suatu media untuk 
menyampaikan ide, teori, atau penyampaian ideide yang diterapkan dan dirasakan sastrawan tentang kehidupan manusia.

Novel merupakan gambaran suatu kejadian yang luar biasa dari kehidupan pelakunya. Novel merupakan roman yang lebih pendek. Ambary (1983) mengemukakan bahwa novel merupakan cerita yang menceritakan suatu kejadian yang luar biasa dari kehidupan pelakunya yang menyebabkan perubahan sikap dan menentukan nasib.

Sosiologi dan sastra pada hakikatnya mempunyai pokok permasalahan yang sama. Seperti halnya sosiologi, sastra juga berurusan dengan manusia dalam masyarakat sebagai usaha manusia untuk menyesuaikan diri dan usahanya untuk mengubah masyarakat. Dengan demikian, novel dapat dianggap sebagai usaha untuk menciptakan kembali dunia sosial, yaitu hubungan manusia dengan keluarga, lingkungan, politik, negara, ekonomi, dan sebagainya yang juga menjadi urusan sosiologi. Dapat disimpulkan bahwa sosiologi dapat memberi penjelasan yang bermanfaat tentang sastra, dan bahkan dapat dikatakan bahwa tanpa sosiologi, pemahaman kita tentang sastra belum sempurna.

Sosiologi merupakan ilmu yang mempelajari mengenai keadaan manusia dalam suatu masyarakat. Gerak gerik, tingkah laku, komunikasi dalam lingkungan masyarakat. Shadily mengungkapkan bahwa sosiologi adalah ilmu yang mempelajari hidup bersama dalam masyarakat, dan menyelidiki ikatan-ikatan antar manusia yang menguasai kehidupan itu (Shadily, 1989:11).

\section{METODE}

Metode yang digunakan dalam penelitian ini adalah metode deskriptif dengan analisis isi dengan mendeskripsikan aspek sosiologi karya sastra ada dalam novel Menggapai Matahari karya Dermawan Wibisono. Objek penelitian ini adalah aspek sosiologi karya sastra pada novel Menggapai Matahari karya Dermawan Wibisono diterbitkan oleh Inti Medina, Jakarta, September 2010, 354 halaman.

Fokus dalam penelitian ini adalah aspek sosiologi karya sastra novel Menggapai Matahari karya Dermawan Wibisono. Aspek sosiologi karya sastra dilihat dari, yang mempermasalahkan karya sastra itu sendiri yaitu sistem politik, sistem kepercayaan, sistem ekonomi, sistem pendidikan, dan apa yang menjadi pokok permasalahan adalah apa yang tersirat dalam karya sastra, dan apa yang menjadi tujuannya atau amanat yang hendak disampaikan.

\section{HASIL DAN PEMBAHASAN}

Novel Menggapai Matahari karya Dermawan Wibisono danalisis berdasarkan unsur sistem sosial, sistem nilai dan ide, dan peralatan budaya. Aspek sosiologi sastra yang ditemukan meliputi, (1) unsur sistem sosial, yakni sistem politik sebanyak 3 poin, sistem kepercayaan sebanyak 7 poin, sistem ekonomi sebanyak 2 poin, dan sistem pendidikan/se-banyak 7 poin, (2) sistem nilai sebanyak 2 poin dan sistem ide sebanyak 3 poin, dan (3) peralatan budaya sebanyak 3 poin.

\section{Unsur Sistem Sosial}

Unsur sistem sosial yang ditemukan dalam novel Menggapai Matahari mencakup sistem politik, sistem ekonomi, sistem kepercayaan, dan sistem pendidikan. Uraian setiap temuan dipaparkan sebagai berikut.

\section{Sistem Politik}

Sistem politik adalah sebagai pola yang tetap dari hubungan-hubungan antar manusia yang melibatkan, sampai dengan tingkat yang berarti, kontrol, pengaruh, kekuasaan, ataupun wewenang.

\footnotetext{
"Para anggota PKI, terutama para pembesarnya, memang pandai dalam agitasi dan menarik massa. Para seniman kondang pun banyak yang ikut kelompok Lekra, lembaga kebudayaan rakyat bentukan PKI yang memberangus karya-karya yang berbeda mazhab dengan kelompok mereka. Tak kurang karya-karya almarhum Hamka dihajar dan dihujat habis oleh kelompok Lekra di bawah kendali Pramoedya Ananta Toer." (hlm. 103)
}

Dari petikan kalimat di atas, anggota PKI menarik massa sebanyak mungkin untuk membentuk kelompok lembaga kebudayaan rakyat atau yang biasa disebut Lekra. Kelompok tersebut menghujat karya-karya Hamka karena 
mengganggap karya Hamka berbeda mazhab dengan kelompok mereka.

\begin{abstract}
"Kolonel Untung, komandan pasukan Cakrawibawa, pasukan pengawal Presiden Sukarno, yang biasa menjadi penggerak lapangan PKI, memulai karirnya di Kesatuan Banteng Raiders di Srodol, Semarang. Kariernya cukup cemerlang sehingga punya pengikut yang cukup banyak, bukan saja dari kalangan tentara, tapi juga dari masyarakat. Masyarakat terpecah dalam kebingungan dan pilihan sulit: pilihan hidup-mati. Di Banyumanik tinggal keluarga kita, keluarga Mbah Sastro, dan keluarga besar Pak Lurah yang masih Nasionalis-Agamis, yang hampir semuanya menjadi pengikut PKI. Ada yang jadi tokoh, seperti Kolonel Untung itu, ada juga yang cuma ikut-ikutan." (hlm. 102)
\end{abstract}

Dari petikan kalimat di atas, PKI memiliki pengikut yang banyak sehingga membuat masyarakat pada saat itu kebingungan dan pilihan yang sulit, pilihan hidup atau mati. Mereka bingung antara harus menjadi pengikut PKI atau menjadi nasionalis-agamis.

\begin{abstract}
"Kalo Lik Sirkan tetangga depan rumah kita uang rumahnya di samping kiri Mbah Jawari, itu termasuk tokoh. Bahkan menjelang pemberontakan meletus, dia berjalan keliling desa dan berkoar anak mencucup darah orang-orang yang tidak beraliansi PKI. Jika PKI menang saat itu, maka orangorang seperti Lik Sarkam akan ber-pesta pora seperti kerasukan setan, mem-bunuh orang-orang kampong yang tidak se-paham dengan dirinya. Padahal di kam-pung kita, tinggal keluarga besar Pak Lurah Mardi, Mbah Sastro, dan ayah saja yang tidak ikut PKI." (hlm. 104)
\end{abstract}

Dari petikan di atas, Lik Sirkam adalah orang yang beraliansi PKI. Jika PKI menang pada saat itu, maka ia akan berpesta pora, ia akan membunuh orang-orang yang tidak sepaham dengannya yaitu beraliansi PKI.

\section{Sistem Kepercayaan}

Sistem kepercayaan adalah pemahaman terhadap segala aspek alam semesta yang dianggap sebagai suatu kebenaran. Kepercayaan juga merupakan ketundukan atau penyerahan diri kepada kekuatan yang lebih tinggi dari pada manusia yang dipercayai mengatur dan mengendalikan jalannya alam dan kehidupan umat manusia. Kepercayaan itu ditandai dan disertai dengan ketundukan dan penyerahan diri serta menjalankan ajaran-ajaran dan kewajiban sesuai dengan kepercayaan itu sendiri.

\begin{abstract}
"Inalilahi wa inna ilaihi raji'un...! Serentak anak-anak dalam kelas mengucapkan kalimat duka cita tanpa di komando. Semua yang berasal dari-Nya akan kembali kepada-Nya." (hlm. 66)
\end{abstract}

Semua yang berasal dari tanah akan kembali ke tanah. Dunia ini hanya sesaat, dunia yang abadi adalah dunia akherat. Dan di akheratlah dosa dan amal kita sebagai umat manusia akan iperhitungkan.
"Mereka menahan tangis dengan susah pa- yah. Bibir-bibir mungil gemetar, mata-mata beningtergenang air mata. Ya Allah... Ya Rabbi... Ya Malik... Ya Kudus... Yang memberi kehidupan... Yang menentukan takdir bagi umat-Nya... Engkau cabut nya- wa guru kesayangan kami begitu cepatnya. Mungkinkah kehidupan di sana lebih baik dari kehidupan di dunia yang begitu sulit- nya di kampong kami ini?" (hlm. 67)

Dari petikan kalimat di atas, kematian bisa datang sewaktu-waktu, tidak ingat muda atau tua, tidak ingat sedang susah ataupun senang, tidak peduli saat sakit ataupun sehat. Yang harus kita ingat adalah bekal untuk menuju alam setelah dunia.

"Allah akan memberikan tempat dan pahala yang mulia bagi muslimin dan muslimat yang membantu saudara-saudaranya terbebas dari lilitan hutang" (hlm. 71)

Dari petikan kalimat di atas, sesama umat Islam harus saling menolong. Jika ada kerabat yang meninggal dan yang tersebut masih mempunyai sejumlah utang, baiknya membantu untuk membebaskan hutangnya, karena Allah akan memberikan tempat dan pahala yang mulia bagi umat-Nya yang membantu saudara-saudaranya terbebas dari lilitan hutang.

"Bimo tak dapat memejamkan mata semalaman. Inilah pertaruhan pertama dala hidupnya. Pertaruhan untuk menjadi pemenang atau pecundang. Diambilnya air 
wudu ketika malam tinggal tersis a sepertiga. Ditunaikannya salat tahajud, mohon kepada-Nya agar dibukakan pintu kemudahan, dimudahkan dalam segala urusan, dan dihindarkan semua kesulitan yang tak mampu ditanggungnya." (hlm. 135)

Dari petikan kalimat di atas, dengan menunaikan salat tahajud dan berdoa kita dapat ketenangan. Kita meminta agar semua diberi kemudahan dan kelancaran dalam segala urusan dan dijauhkan dari semua kesulitan karena sesungguhnya hanya kepada Allah kita berdoa dan meminta.

\begin{abstract}
"Ayah Bimo orang gunung dengan latar belakang Islam ndeso yang biasa ngaji di langgar kampung, tadarusan, puji-pujian, rebutan nabuh bedug dan kentongan, dan arak-arakan dengan obor di tangan saat malam lebaran datang. Tak mementingkan ceremony, lebih ke substansi. Tak percaya adanya hari baik-hari buruk. Jodoh bukan ditentukan perhitungan wetton, tetapi oleh kesamaan akidah dan rasa saling mencintai. Tidak perlu melakukan banyak upacara yang tidak dicontohkan nabi karena dapat menjurus ke bid'ah. Makan dengan tangan dan sendok garpu pun tak mengapa, karena toh rasul mencontohkannya begitu." (hlm. 127)
\end{abstract}

Dari petikan kalimat di atas, Ayah Bimo adalah orang gunung yang tidak mempercayai hal-hal yang bersifat kejawen, seperti jodoh diperhitungankan dari tanggal lahir, percaya hari baik atau hari buruk. Ia lebih percaya dengan yang diajarkan oleh Islam. Baginya jika hal tersebut tidak dicontohkan nabi dan tidak ada dalam Islam, maka ia tidak perlu melakukannya.

\footnotetext{
"Sedangkan Bu Prapti beragama Islam namun lebih kental dengan tata cara kejawen dan keningratannya. Penuh perhatian pada berbagai upacara adat, mitoni-selametan tujuh bulan bayi yang dikandung, tedak sinten-upacara perayaan jika anak sudah mulai belajar berjalan, nyatus dan nyewuselamatan hari keseratus dan keseribu bagi kerabat yang meninggal dunia. Memperhitungkan hari baik dan buruk. Menghitungkan kecocokan berdasarkan nilai hari dan nilai pasaran kelahiran pasangan." (hlm. 127-128)
}

$\mathrm{Bu}$ Prapti adalah turunan ningrat, walaupun ia orang Islam namun lebih kental dengan tata cara kejawen. Dengan melakukan berbagai adat upacara, seperti upacara tujuh bulan dan perayaan jika anak sudah mulai berjalan. Baginya melakukan upacara seperti itu merupakan adat bagi orang jawa yang harus dilakukan, apalagi ia merupakan turunan ningrat walaupun dalam agama Islam tidak diajarkan hal-hal semacam itu.

\begin{abstract}
"Rejeki tak akan lari kemana. Allah sudah merencanakan dan mengaturnya dengan rapi, manusia hanya berupaya dengan segala daya dan menyerahkan hasilnya kepada-Nya. Kadang kala, Allah membuka rejeki dan melonarkannya lewat pintu dan jendela yang tak terduga, yang tiba-tiba terkuak di hadapan manusia. Demikian pula yang diterima anak-anak kelas unggulan itu dalam tahun terakhir masa studi mereka." (hlm. 263)
\end{abstract}

Dari petikan kalimat di atas, rejeki manusia sudah ada yang mengatur, yaitu Allah Swt. Jadi sebagai manusia kita hanya bisa berusaha dan kerja keras untuk melakukan yang terbaik serta diimbangi dengan ibadah dan berdoa sedangkan hasilnya kita serahkan kepada Allah Swt.

\section{Sistem Ekonomi}

Sistem ekonomi merupakan suatu kumpulan dari aturan atau kebijakan yang saling berkaitan dalam upaya memenuhi kebutuhan untuk mencapai kemakmuran. Sistem ekonomi ini juga berkaitan dengan hubungan manusia dengan perekonomiannya yang sangat erat hubungannya dengan bagaimana kita mencukupi kebutuhan manusia tersebut.

"Kami diberitahu tengah malam tadi bahwa ayah gugur dalam tugas di Timor Timur, Bu. Beliau tertembak, Bu...hu...hu...hu! saat... saat menerima kabar itu, ibu langsung pingsan. Penyakit jantung ibu kumat dan segera dilarikan ke rumah sakit, Bu. Tapi...tapi...kami tidak punya uang untuk biaya pengobatan ibu, jadi kami mencuri kacang di sekolah dan menjualnya ke penjual kacang rebus di pasar." (hlm. 62)

Dari petikan di atas, bagaimana seorang anak yang terpaksa mencuri kacang, ia menjadi 
pencuri kacang karena untuk mencari biaya pengobatan ibunya yang sedang sakit. Sedangkan ia tak mempunyai biaya karena ayahnya yang biasanya mencari nafkah dan menjadi pilar keluarganya telah gugur dalam tugas di Timor Timur.

\begin{abstract}
"Dia masih lebih beruntung dibandingkan dengan teman-teman kampung dan temanteman SD-nya dulu yang harus menjadi buruh pabrik di usia muda, seperti Megeng dan Jumino atau bahkan harus kawin muda, seperti Poniyem, Sartini, Surahmi, dan Jamilah karena harus memenuhi kebutuhan ekonomi keluarganya." (hlm. 264)
\end{abstract}

Dari petikan kalimat di atas, Bimo berasa bahwa ia lebih jauh beruntung dibandingkan dengan teman-temannya yang harus putus sekolah karena harus bekerja di pabrik atau menikah di usia muda dengan orang yang kaya untuk membantu dan memenuhi kebutuhan ekonomi keluarganya.

\section{Sistem Pendidikan}

Pendidikan sebagai pengalaman belajar yang berlansung dalam segala lingkungan hidup dan sepanjang hidup, baik di sekolah atau di luar sekolah, karena pendidikan merupakan segala situasi yang memengaruhi pertembuhan seseorang sebagai suatu proses pengembangan diri individu dan kepribadian seseorang yang dilaksanakan secara sadar, serta nilai-nilai penyesuaian diri dengan lingkungan.

\footnotetext{
"Dendam di sanubari Bimo membangun pondasi hati dan menumbuhkan sikap pantang menyerah, keras kemauan, dan citacita tinggi untuk menjadi orang yang selalu ingin memberik." (hlm. 33)
}

Berusaha meraih cita-cita dengan kerja keras, kemauan besar dan sikap pantang menyerah untuk membuktikan kepada semua orang bahwa ia bisa meraih cita-cita dan patut untuk dibanggakan.

"Bimo belajar dengan keras, begitu keras, siang dan malam. Belajar bagai mengejar bayang-bayang. Semua itu ia lakukan demi meraih kembali kasih sayang yang hilang. Meraih kembali kehangatan sosok ibu yang tercampakkan. Di sekolah Bimo begitu aktif dan ambisius meraih berbagai posisi dan prestasi. Bimo menjadi juara umum rangking satu sekolah yang meninggalkan jauh pesaingnya, menjadi juara lomba apa pun yang bisa ia ikuti ; lomba lawak, lomba nyanyi, lomba gambar. Semua lomba. Untuk sekedar merengkuh kasih sayang ibu yang terenggut darinya. Bimo menjelma menjadi sosokyang haus kasih sayang, perhatian, belai lembut wanita, dan suara yang menentramkan hati." (hlm. 124-125)

Dari petikan di atas, selalu belajar dengan keras tak kenal waktu, semua itu dilakukan untuk membuka hati ibunya yang sudah beku karena ramalan laknat dan mendapatkan kasih sayang serta perhatian yang sudah lama tidak ia rasakan. Dengan belajar dan selalu mendapatkan prestasi, Bimo membuktikan kepada ibunya bahwa ia bisa, dibanggakan. Itu terbukti dengan diraihnya beberapa prestasi dan menjadi juara lomba apa pun.
"Bimo menikmati segala macam peran dan lomba yang dia ikuti. Dia ingin menjadi manusia multitalenta seperti Leonardo da Vinci, Sir Isaac Newton, Galileo Galilei, dan para ilmuwan di abad pertengahan yang mumpuni dalam ilmu pengetahuan, mampu melukis, pintar matematika, dan jago ilmu astronomi, serba bisa. Bimo ingin menjadi seperti itu." (hlm. 130)

Berbagai lomba dia ikuti, karena dia ingin menjadi manusia yang serba bisa hal apa saja, seperti para ilmuwan di abad pertengahan yang pandai dalam matematika, melukis, dan ilmu astronomi.
"Ya pak, terimakasih, "jawab Bimo sedikit terhibur. Dipatrinya kuat-kuat dalam hati niat dan tekad yang menggumpal bahwa dia bukan hanya mau rangking satu di ke-las, tapi diseluruh sekolah. Aku mau men-jadi juara umum. Aku mau menjadi anak kebanggaan ibu. Aku mau mementahkan ramalan Pak Dhe Sugeng. Aku mau meraih masa depanku yang cemerlang." (hlm. 139)

Dari petikan di atas, Bimo bertekad untuk selalu menjadi nomor satu, tidak hanya di kelas tetapi juga di sekolah. Dia ingin menjadi juara umum. Dia ingin mempunyai masa depan yang cemerlang dan dia ingin menjadi anak kebanggaan ibunya serta ingin mementahkan ramalan Pak Dhe Sugeng. 
"Setelah sekian detik menunggu dan tak ada seorang pun yang maju, Bimo dengan setengah berlari dan kepala menunduk menuju ke tengah lapangan upacara menjajarkan diri dibarisan para juara yang telah menunggu. Piagam penghargaan dari Kepala Sekolah diterimanya dengan takjub. Benarkah ini untukku? Rangking pertama masuk sekolah dari 550 siswa yang diterima di sekolah ini. Padahal total pendaftaran berjumlah 1.500 orang. Wuuuaahh... hebat juga aku ya? Bimo masih belum percaya. Semuanya bagi mimpi." (hlm. 171)

Saat upacara Bimo mendapatkan piagam penghargaan karena menjadi rangking pertama masuk sekolah dari 550 siswa yang diterima. Bimo sangat terkejut dan tidak percaya, ia merasa ini hanya mimpi.

\footnotetext{
"Selama sebulan penuh Bimo bangun jam tiga dini hari, sholat tahajud, belajar dan terus belajar tanpa henti sampai malam hari, hanya diselingi jeda sholat dan makan saja. Bimo bukan hanya belajar bahanbahan dan contoh-contoh tes masuk SMA warisan Kresno saja. Bimo bahkan sekalian belajar bahan pelajaran di SMA. Pelajaran SMA kakaknya kelas 1 dan 2 dilalap habis." (hlm 174)
}

Dari petikan kalimat di atas, untuk tes masuk SMA. Bimo belajar dengan keras. Selama sebulan penuh hari-hari Bimo hanya di isu dengan belajar dan belajar, ia mengerjakan contohcontoh soal masuk SMA. Semua itu ia lakukan untuk dapat masuk di SMA favorit pilihannya.

\footnotetext{
"Bimo ingin berprestasi untuk dirinya sendiri, untuk masa depan yang lebih baik, bukan untuk siapa-siapa. Orang tuanya mau membiayaisekolahnya sampai sejauh ini sudah sangat ia syukuri. Itu berarti dia masih lebih beruntung dibandingkan teman-teman kampung dan teman-teman Sdnya dulu yang harus menjadi buruh pabrik di usia muda seperti Megeng dan Jumino atau bahkan harus kawin muda seperti Poniyem, Sartini, Surahmi, dan Jamilah karena harus memenuhi kebutuhan ekonomi keluarganya." (hlm 264)
}

Dari petikan kalimat di atas, Bimo sangat beruntung karena bisa sekolah sampai SMA dibandingkat teman-temannya yang harus putus sekolah. Menjadi buruh pabrik atau menikah dini dengan orang kaya. Itu semua dilakukan untuk menafkahi keluarganya untuk itu Bimo ingin menggapai masa depan yang lebih baik dengan belajar dan berprestasi di sekolah.

\section{Sistem Nilai dan Ide}

Sistem nilai yaitu sistem yang memberi makna kepada kehidupan masyarakat, bukan saja terhadap alam sekeliling, bahkan juga terhadap falsafah hidup masyarakat itu. Sistem nilai juga menyangkut bagaimana kita menentukan sesuatu lebih berharga dari yang lain.

\begin{abstract}
"Bu Prapti, cinta adalah pilihan, dengan siapa kelak dia akan melabuhkan hati dan mengarungi samudera kehidupan untuk tiga perempat sisa hidupnya. Oleh karena itu, wanita berhak untuk memilih dan menolak. Sebuah prinsip yang belum ja-mak, bahkan cenderung revolusioner pada zamannya. Bu Prapti berpikir dan bertindak mendahului pola pikir generasi zamannya. Dia seorang yang cerdas dan progresif, pengikut jejak Raden Ajeng Kartini sejati.” (hlm. 32)
\end{abstract}

Dari petikan kalimat di atas, kalimat tersebut mengandung sistem nilai yaitu $\mathrm{Bu}$ Prapti menganggap bahwa wanita berhak menolak atau memilih ceritanya. Walaupun Bu Prapti merupakan keturunan priyayi yang bisa dijodohkan oleh orang tuanya namun $\mathrm{Bu}$ Prapti tidak mengikuti tradisinya. Ia mempunyai prinsip hidup sendiri. Baginya cinta adalah pilihannya bukan pilihan orang lain.

\footnotetext{
"Pak Prapto lebih banyak mengalah. Mengalah untuk kebaikan. Untuk kebutuhan rumah tangga dan masa depan anaknya. Bagi Pak Prapto adalah artinya percekokan dibandingkan dengan masa depan anakanaknya yang tergadai jika kedua orang tuanya berpisah." (hlm. 129)
}

Pak Prapto lebih sering mengalah kepada istrinya $\mathrm{Bu}$ Prapti, bagi Pak Prapto keutuhan rumah tangga jauh lebih npenting dari apapun, ia tidak ingin masa depan anak-anaknya suram karena orang tuanya berpisah. Sistem Ide merupakan pengetahuan dan kepercayaan yang terdapat dalam sebuah masyarakat.

"Metode turun temurun telah diterapkan dan dipercayai keampuhannya dalam 
mengungkap tindak kejahatan kembali akan diuji kemanjurannya. Kepala Sekolah memanggil Mbah Ronggo, dukun trisakti di kawasan Banyumanik dan sekitarnya yang konon bisa menyantet orang dan membuat perut yang disantet busung menggelembung penuh dengan tali rafia, ijik, pecah kaca, dan jarum pentul didalamnya." (hlm. 55)

Dari petikan kalimat di atas, untuk mengungkap tindak kejahatan, kepala sekolah menggunakan metode turun temurun yaitu dengan memanggil dukun sakti.

"Ayah Bimo orang gunung dengan latar belakang Islam ndeso, yang biasa ngaji di langgar kampung, tadarusan, puji-pujian, rebutan nabuh bedug dan kentongan, dan arak-arakan dengan obor di tangan saat malam lebaran datang. Tak mementingkan ceremony, lebih ke substansi. Tak percaya adanya hari baik-hari buruk. Jodoh bukan ditentukan perhitungan wetton, tapi oleh kesamaan akidah dan rasa saling mencintai. Tidak perlu melakukan banyak upacara yang tidak dicontohkan nabi karena dapat menjurus ke bid'ah. Makan dengan tangan dan sendok garpu pun tak mengapa, karena toh rasul mencontohkannya begitu." (hlm. 127)

Dari petikan kalimat di atas, Ayah Bimo adalah orang gunung yang tidak mempercayai hal-hal yang bersifat kejawen seperti, jodoh diperhitungankan dari tanggal lahir, percaya hari baik atau hari buruk. Ia lebih percaya dengan yang diajarkan oleh Islam. Baginya jika hal tersebut tidak dicontohkan nabi dan tidak ada dalam Islam, maka ia tidak perlu melakukannya.

\footnotetext{
"Sedangkan $\mathrm{Bu}$ Prapti beragama Islam namun lebih kental dengan tata cara kejawen dan keningratannya. Penuh perhatian pada berbagai upacara adat, mitoni-selametan tujuh bulan bayi yang dikandung, tedak sinten upacara perayaan jika anak sudah mulai belajar berjalan, nyatus dan nyewu-selamatan hari keseratus dan keseribu bagi kerabat yang meninggal dunia. Memperhitungkan hari baik dan buruk. Menghitungkan kecocokan berdasarkan nilai hari dan nilai pasaran kelahiran pasangan.” (hlm. 127-128)
}

$\mathrm{Bu}$ Prapti adalah turunan ningrat, walaupun ia orang Islam namun lebih kental dengan tata cara kejawen. Dengan melakukan berbagai adat upacara seperti, upacara tujuh bulan dan perayaan jika anak sudah mulai berjalan. Baginya melakukan upacara seperti itu merupakan adat bagi orang jawa yang harus dilakukan, apalagi ia merupakan turunan ningrat walaupun dalam agama Islam tidak diajarkan hal-hal semacam itu.

\section{Peralatan Budaya}

Peralatan budaya, yaitu pencipta material yang berupa perkakas dan peralatan yang diperlukan untuk menunjang kehidupan.

\section{"Ayah Bimo orang gunung dengan latar belakang Islam ndeso, yang biasa ngaji di langgar kampung, tadarusan, puji-pujian, rebutan nabuh bedug dan kentongan, dan arak-arakan dengan obor di tangan saat malam lebaran datang." (hlm. 127)}

Dari petikan kalimat di atas, Ayah Bimo bisa ngaji di langgar kampung, tadarusan, pujipujian, rebutan nabuh bedug dan kentongan, dan arak-arakan dengan obor di tangan saat malam lebaran datang.

"Makan dengan sendok dan garpu tak boleh berdenting karena beradu dengan piring." (hlm 128)

Dari petikan di atas, bagi orang jawa khususnya keturunan priyayi makan dengan sendok dan garpu tidak boleh beradu dan berbunyi karena bagi orang jawa itu dianggap tidak sopan.

\footnotetext{
"Menuang air minum di gelas harus margin kosong satu sentimeter dari bibir gelas." (hlm. 128)
}

Bagi orang Jawa menuang air minum di gelas harus margin kosong satu sentimeter dari bibir gelas karena itu merupakan adat kesopanan orang Jawa.

\section{SIMPULAN}

Novel Menggapai Matahari karya Dermawan Wibisono mengandung aspek sosiologi karya sastra, meliputi unsur sistem sosial 
yang menckaup sistem politik sebanyak 3 poin, sistem kepercayaan sebanyak 7 poin, sistem ekonomi sebanyak 2 poin, dan sistem pendidikan sebanyak 7 poin. Dari hasil analisis unsur sistem sosial meliputi sistem politik, sistem kepercayaan, sistem ekonomi, dan sistem pendidikan. Hasil analisis menunjukkan bahwa Novel Menggapai Matahari terlihat bahwa lebih menitik beratkan sistem kepercayaan dan sistem pendidikan. Dominasi sistem kepercayaan terlihat dari tokoh Bimo yang percaya kepada kekuatan yang lebih tinggi dari pada manusia yang dipercayai mengatur dan mengendalikan jalannya alam dan kehidupan umat manusia, yaitu Allah Swt. Kepercayaan itu ditandai dan disertai dengan ketundukan dan penyerahan diri serta menjalankan ajaran-ajaran dan kewajiban sesuai dengan kepercayaan itu sendiri, seperti sholat dan berdoa. Begitu pula tokoh Bu Prapti yang sangat percaya dengan hal-hal yang bersifat kejawen, seperti upacara adat, mitoni (selametan tujuh bulan bayi yang dikandung), tedak sinten (upacara perayaan jika anak sudah mulai belajar berjalan), nyatus dan nyewu (selametan hari keseratus dan keseribu bagi kerabat yang meninggal dunia). Memperhitungkan hari baik dan buruk. Menghitung kecocokan berdasarkan nilai hari dan nilai pasaran kelahiran pasangan.

\section{DAFTAR PUSTAKA}

Ambary, Abdullah. 1983. Intisari Sastra Indonesia. Bandung: Djanika

Shadily, Hassan. 1989. Sosiologi untuk Masyarakat. Jakarta: Bina Aksara
Sistem nilai sebanyak 2 poin dan sistem ide sebanyak 3 poin. Dari analisis terlihat jelas bahwa lebih menitik beratkan sistem ide yang merupakan pengetahuan dan kepercayaan yang terdapat dalam sebuah masyarakat. Dominasi tersebut dapat dilihat dari tokoh Ayah Bimo tidak mempercayai hal-hal yang bersifat kejawen, seperti jodoh diperhitungkan dari tanggal lahir, percaya hari baik atau hari buruk. Ia lebih percaya dengan yang diajarkan oleh Islam. Baginya jika hal tersebut tidak dicontohkan nabi dan tidak ada dalam Islam, maka ia tidak perlu melakukannya.

Peralatan budaya sebanyak 3 poin. Dominasi peralatan budaya banyak ditemukan pada tokoh Bu Prapti yang menganggap bahwa orang jawa khususnya keturunan priyayi, makan dengan sendok dan garpu tidak boleh beradu dan berbunyi karena bagi orang jawa itu dianggap tidak sopan. Menuang air minum di gelas harus margin kosong satu sentimeter dari bibir gelas karena itu merupakan adat kesopanan orang jawa.

Dari unsur sistem sosial, sistem nilai dan ide, dan peralatan budaya, penulis menyimpulkan bahwa unsur sistem sosial yang meliputi; sistem politik, sistem kepercayaan, sistem ekonomi, dan sistem pendidikan lebih dominan dalam novel Menggapai Matahari.

Teeuw, A. Sastra dan Ilmu Sastra. 1984. Jakarta : PT Pustaka Jaya

Wellek, Renne dan Austin Warren. 1997. Teori Kesusastraan. Terjemahan melalui Budianta. Jakarta: Gramedia 